\title{
Um estudo sobre a certificação ISO 9001 no Brasil: mapeamento de motivações, benefícios e dificuldades
}

\section{Study on ISO 9001 certification in Brazil: mapping the motivations, benefits, and difficulties}

\author{
Rafael Maekawa ${ }^{1}$ \\ Marly Monteiro de Carvalho \\ Otávio José de Oliveira ${ }^{1}$
}

\begin{abstract}
Resumo: O objetivo deste trabalho é identificar as principais motivações, benefícios e dificuldades na certificação de Sistemas de Gestão da Qualidade ISO 9001 em empresas brasileiras. Adicionalmente investigaram-se as principais práticas de gestão da qualidade que dão suporte a este tipo de certificação e qual o seu relacionamento com outros tipos de sistemas, tais como a ISO 14001 (Gestão Ambiental) e a OHSAS 18001 (Gestão da Segurança e Saúde do Trabalho). A abordagem metodológica utilizada foi a pesquisa tipo survey, cuja amostra conteve 191 empresas. As principais motivações para implementação da ISO 9001 identificadas foram: possibilidade de melhoria na organização interna, maior eficiência produtiva e maior confiabilidade na marca. A resistência dos funcionários foi apontada como a maior dificuldade. Já os principais benefícios obtidos foram: melhoria da qualidade nos processos e maior conscientização dos empregados em relação à qualidade. Os resultados revelam que os programas e ferramentas da qualidade mais utilizados são: 5S, brainstorming e diagrama de Ishikawa; enquanto os menos utilizados são: o Servqual e o QFD.
\end{abstract}

Palavras-chave: ISO 9001. Gestão da qualidade. Programas da qualidade. Ferramentas da qualidade.

\begin{abstract}
This work aims to identify the main motivations and difficulties faced by Brazilian companies to obtain ISO 9001 certification. The key quality management practices that provide support to this certification and the relationship with other types of systems, such as ISO 14001 (Environmental Management) and OHSAS 18001 (Occupational Health and Safety Management System), were also investigated. A survey research was conducted with 191 companies. The main motivations for implementing ISO 9001 are the following: internal organization improvement, production efficiency increase, and brand reliability improvement. Employee resistance was the greatest challenge found during the implementation process. On the other hand, the main benefits identified were: quality processes improvement and increased employee awareness of quality. The results reveal that the most common quality programs and tools used are: $5 \mathrm{~S}$, brainstorming, and Ishikawa diagram, while the least common are SERVQUAL and QFD.
\end{abstract}

Keywords: ISO 9001. Quality management. Quality programs. Quality tools.

\section{Introdução}

As empresas atuam em um ambiente complexo, com intensas mudanças tecnológicas e constantes alterações nos padrões de exigências dos consumidores. Este cenário conturbado faz com que elas tenham que se adaptar constantemente para não perderem espaço no mercado. Em face disto, faz-se necessário desenvolver e implantar instrumentos tecnológicos e gerenciais que gerem consistentes vantagens competitivas para sua distinção positiva.

Os sistemas de gestão da qualidade (SGQ) são uma interessante alternativa para esta geração de vantagem, pois eles desenvolvem um padrão de melhoria a partir da motivação do quadro de colaboradores, do controle de processos, da identificação de requisitos e atendimento das necessidades dos clientes (CALARGE; LIMA, 2001).

Contudo, utilizar corretamente estes instrumentos é condição fundamental para que deles se obtenha seus potenciais resultados. É comum encontrar dificuldades no seu entendimento conceitual, resistência ao seu uso, baixa disponibilização de recursos para seu desenvolvimento e manutenção, treinamento

\footnotetext{
${ }^{1}$ Departamento de Produção, Faculdade de Engenharia de Guaratinguetá - FEG, Universidade Estadual Paulista - UNESP, Av. Ariberto Pereira da Cunha, 333, Pedregulho, CEP 12516-410, Guaratinguetá, SP, Brasil, e-mail: rafael_maekawa@msn.com; otaviodeoliveira@uol.com.br

${ }^{2}$ Departamento de Engenharia de Produção, Escola Politécnica - POLI, Universidade de São Paulo - USP, Av. Almeida Prado, travessa 2, 128, Cidade Universitária, CEP 05508-010, São Paulo, SP, Brasil, e-mail: marlymc@usp.br
}

Recebido em 27/9/2012 — Aceito em 4/7/2013

Suporte financeiro: $\mathrm{CNPq}$. 
inadequado ou mesmo desconhecimento de sua existência (BATTIKHA, 2003).

O objetivo deste artigo é identificar as principais motivações, benefícios e dificuldades na certificação de SGQs ISO 9001 em empresas brasileiras. Adicionalmente investigaram-se as principais práticas (programas e ferramentas) da gestão da qualidade que dão suporte a este tipo certificação e qual o seu relacionamento com outros tipos de sistemas, tais como a ISO 14001 (Sistema de Gestão Ambiental) e a OHSAS 18001 (Sistema de Gestão da Saúde e Segurança do Trabalho).

A abordagem metodológica utilizada foi a pesquisa tipo survey em 191 empresas brasileiras certificadas segundo a norma ISO 9001 (INTERNATIONAL..., 2008) constante da base de dados do INMETRO (Instituto Nacional de Metrologia, Normalização e Qualidade Industrial). Os procedimentos metodológicos serão mais bem esclarecidos na Seção 3.

Este artigo está estruturado em 6 Seções. Depois desta introdução, apresenta-se a síntese do referencial teórico (Seção 2) que deu suporte ao desenvolvimento do trabalho, seguido do método de pesquisa (Seção 3). As seções 4 e 5 apresentam, respectivamente, os resultados obtidos e a sua discussão e análise. A seção 6 traz as conclusões do estudo, seguida das referências bibliográficas e dos Apêndices.

\section{Fundamentação teórica}

Neste item, será apresentada uma síntese da revisão teórica utilizada para realização da pesquisa.

\subsection{Gestão da qualidade}

A qualidade de bens e serviços deve ser encarada como uma questão maior na empresa e não mais como um aspecto apenas voltado ao setor de produção (SLACK; CHAMBERS; JOHNSTON, 2002). Com a competitividade atingindo níveis cada vez mais elevados, as empresas passaram a observar a forma como produzem seus bens e serviços sob uma nova ótica. Elas devem ter a excelência como uma meta contínua, de maneira a conseguirem vantagem competitiva no contexto em que estão inseridas (BATTIKHA, 2003). Este movimento fez com que as empresas se organizassem e adotassem SGQs para ajudá-las a alcançar seus objetivos (PINTO; CARVALHO; HO, 2006).

Gestão de qualidade é um conjunto de ações coordenadas que permitem gerenciar uma organização, objetivando a satisfação dos agentes intervenientes, o que inclui, principalmente, o cliente externo (DOUGLAS; COLEMAN; ODDY, 2003; FRANCESCHINI; GALLETO; CECCONI, 2006).

Para Lagrosen e Lagrosen (2003), um SGQ é uma reunião de técnicas e modelos de gerenciamento que visam à qualidade, tanto no setor de manufatura como no setor de serviços. Ele pode ser empregado em instituições de qualquer porte e nacionalidade (MACHADO; ROTONDARO, 2003).

O SGQ é uma forma de gestão definida pela alta direção que se fundamenta na identificação de requisitos dos clientes, padronização de processos e melhoria contínua (VALLS, 2005; UENO, 2008).

\subsection{Sistemas de gestão ISO 9001}

A International Organization for Standardization é a responsável pelas normas ISO em todo o mundo. Trata-se de uma organização internacional com sede em Genebra, fundada em 1946, que objetiva o desenvolvimento de normas técnicas para aplicação mundial, possuindo grande representatividade no estabelecimento de padrões internacionais para a gestão (CORREIA; MELO; MEDEIROS, 2006; GALBINSKI, 2008).

As normas ISO 9000 são reconhecidas internacionalmente e, em alguns nichos de mercado, têm forte apelo comercial, incentivando vendas e estabelecendo parcerias comerciais (VALLS, 2005; FRANCESCHINI; GALLETO; CECCONI, 2006). A série ou família de normas ISO 9000 é composta pelas seguintes normas: ISO 9000, que apresenta fundamentos e vocabulário; ISO 9001, que é a norma certificável, apresentando os requisitos básicos para um SGQ; e a ISO 9004, que apresenta recomendações para a melhoria do desempenho dos SGQs (CORREIA; MELO; MEDEIROS, 2006).

A norma ISO 9001 é um padrão certificável de qualidade que foca principalmente a obtenção de processos eficazes e clientes satisfeitos. Este padrão é aplicável, pelo menos em tese, a todas as organizações, independente do tipo, tamanho ou produto/serviço oferecido e pode ser considerado um elemento básico e introdutório para estabelecer processos estruturados e organizados, tornando-se a base fundamental para o avanço da qualidade e, consequentemente, da gestão empresarial (DOUGLAS; COLEMAN; ODDY, 2003).

A eficácia dos processos será alcançada por meio da melhoria nas especificações, do seu controle a partir de indicadores, do treinamento da mão de obra e da melhoria contínua do processo em si. Já os clientes ficarão satisfeitos porque os produtos e os processos produtivos deverão ser desenvolvidos com base na sua real necessidade.

A última versão da norma ISO 9001 foi publicada em novembro de 2008, sendo esta sua quarta edição. A ISO 9001:2008 é uma emenda e não a revisão completa da sua versão anterior. Nenhum requisito foi adicionado, porém ela representou uma clarificação dos requisitos já existentes (GALBINSKI, 2008).

A norma ISO 9001 (INTERNATIONAL..., 2008) está baseada no ciclo PDCA (Plan-Do-Check-Act), que também estrutura as normas ISO 14001 e OHSAS 
18001. A ideia é manter um ciclo de melhoria contínua dos padrões de gestão sempre elevando o desempenho a um grau superior, partindo do Plan (planejar): estabelecer os objetivos e processos necessários para produzir resultados de acordo com os requisitos dos clientes e políticas da organização; Do (fazer): implementar os processos; Check (checar): monitorar e medir processos e produtos em relação às políticas, aos objetivos e aos requisitos e relatar os resultados; e Act (agir): executar ações para promover continuamente a melhoria do desempenho do processo.

\subsection{Motivações para a certificação}

As motivações para a adoção da norma ISO 9001 são discutidas por diversos autores, alguns remetem a suas versões anteriores, como Xavier (1995), Huarng, Horng e Chen (1995), Vloeberghs e Bellens (1996), Anderson, Daly e Johnson (1999), Beattie e Sohal (1999) e Terziovski e Sohal (2000). Enquanto os estudos mais recentes já contemplam a nova versão, que possui maior orientação para gestão por processos, como Sampaio, Saraiva e Rodrigues (2009), Feng, Terziovski e Samson, (2008), Pinto, Carvalho e Ho (2008), Nair e Prajogo (2009), Scott, Wilcock e Kanetkar (2009) e White et al. (2009).

As motivações para a certificação da ISO 9001 podem ser classificadas em duas categorias: motivações internas e motivações externas (RAYNER; PORTER, 1991; VAN DER WIELE; BROWN, 1997; SAMPAIO; SARAIVA; RODRIGUES, 2009; ANDERSON; DALY; JOHNSON, 1999; BEATTIE; SOHAL, 1999).

As internas estão relacionadas com o objetivo de alcançar a melhoria da organização, enquanto as externas estão relacionadas ao marketing, pressões do cliente e aumento do market share (SAMPAIO; SARAIVA; RODRIGUES, 2009). As motivações podem gerar resultados distintos em função do grau de comprometimento dos dirigentes, da conscientização em relação a deficiências empresariais existentes e da disponibilidade de recursos financeiros, físicos e humanos.

Lo e Chang (2007) relacionaram as motivações para a certificação da ISO 9001 com os benefícios obtidos. Para Feng, Terziovski e Samson (2008), o fato de que haja apenas motivações externas pode gerar sérios transtornos ao processo de implantação.

Um dos primeiros estudos realizados no Brasil sobre o tema foi o de Xavier (1995), que destaca as seguintes motivações: reconhecimento internacional (57\%); atualização do sistema de qualidade já existente (27\%); decisão de cúpula no âmbito da corporação (26\%); e exigências contratuais (17\%). Corrobora esta visão Corbett (2005), salientando que uma considerável parte das certificações ISO 9001 pode ser explicada pela pressão exercida por clientes a jusante das cadeias de fornecimento global sobre as empresas situadas em outros países. Isto implica que as empresas exportadoras em uma região também pode simultaneamente importar práticas de gestão.

Estudos internacionais como o de Van der Wiele e Brown (1997), realizado na Austrália, destaca o fator de motivação interno relacionado à melhoria da qualidade e da eficiência, e como externo o marketing. Para Nair e Prajogo (2009), os principais motivos estão relacionados à melhoria da imagem ou reputação e o atendimento das expectativas dos clientes. Scott, Wilcock e Kanetkar (2009), que estudaram empresas canadenses do setor de alimentos, destacam dois fatores internos de motivação: a melhoria do desempenho em qualidade e a melhoria da produtividade. Lo e Chang (2007) estudaram empresas em Taiwan, nas quais as motivações relacionadas a aspectos internos predominaram.

\subsection{Benefícios provenientes da certificação}

De uma forma geral, a literatura apresenta diversos benefícios provenientes do sistema ISO 9001. Eles podem ser sentidos diretamente sobre os principais elementos que compõem a empresa: projeto, produção, produto e cliente (HUARNG; HORNG; CHEN, 1995; SHIH; HUARNG; LIN, 1996; VLOEBERGHS; BELLENS, 1996; VAN DER WIELE; BROWN, 1997; ANDERSON; DALY; JOHNSON, 1999; BEATTIE; SOHAL, 1999; LEE; ZHOU, 2000; BATTIKHA, 2003; LAKHAL; PASIN; LIMAM, 2006; LO; CHANG, 2007; PINTO; CARVALHO; HO, 2008; SCOTT; WILCOCK; KANETKAR, 2009; AL-RAWAHI; BASHIR, 2009; KUMAR et al., 2009).

Os benefícios da certificação estão diretamente relacionados com as características das motivações para a implantação do SGQ, ou seja, quando as empresas se certificam principalmente devido a motivações externas, as melhorias obtidas são, em geral, de natureza externa. Por outro lado, as motivações internas levam aos benefícios de dimensões mais globais (SAMPAIO; SARAIVA; RODRIGUES, 2009).

Estudos apontam que os benefícios internos podem ser relacionados às questões de eficiência e gerenciais. Os relacionados à eficiência são: redução de custos; melhoria da produtividade; redução de setup; redução de tempo de ciclo e tempo de parada de equipamentos; menores tempos de entrega; menores taxas de defeitos; redução de etapas desnecessárias de processos; eliminação de movimentações desnecessárias de produto/pessoal; e redução de reclamações dos consumidores (SHIH; HUARNG; LIN, 1996; VLOEBERGHS; BELLENS, 1996; TERZIOVSKI; SOHAL, 2000; PINTO; CARVALHO; HO, 2008; SAMPAIO; SARAIVA; RODRIGUES, 2009). Já os relacionados à natureza gerencial são: melhoria do ambiente de trabalho; melhoria do sistema de documentação; e clareza na distribuição de 
responsabilidades (MOTWANI; KUMAR; CHENG, 1996; PINTO; CARVALHO; HO, 2008; SAMPAIO; SARAIVA; RODRIGUES, 2009; SCOTT; WILCOCK; KANETKAR, 2009).

Soma-se a isso o fato de que a implantação bem-sucedida de sistemas da qualidade estabelece e aumenta o processo de previsibilidade do produto, aumentando a eficiência, a redução de desperdícios, a qualidade e a lucratividade. Também se verifica redução na variabilidade, no custo de retrabalho, na emissão de resíduos, no tempo de ciclo e no tempo de inatividade dos equipamentos (ZU, 2009; PSOMAS; FOTOPOULOS; KAFETZOPOULOS, 2011).

$\mathrm{O}$ aumento na previsibilidade do produto se dá a partir do consistente estabelecimento de padrões de projeto e de produção, que devem ser eficazmente comunicados aos funcionários e rigidamente seguidos.

Vale destacar que Lo e Chang (2007) não identificaram relacionamento significativo entre a certificação ISO 9001 e o aumento de market share ou da vantagem competitiva, mas apenas aspectos internos como eliminação de erros e redução de retrabalho e refugo.

Lima, Resende e Hasecnclever (2000), em um estudo empírico realizado com 129 empresas brasileiras, compararam o desempenho de organizações certificadas segundo a norma ISO $9001 \mathrm{com}$ um grupo controlado de empresas não certificadas. As evidências indicaram que não havia, à época, diferenças significativas nos resultados empresariais gerais das organizações pesquisadas. Contudo, os pesquisadores concluíram que seria importante e necessário estender e aprofundar o estudo para melhor compreensão desta realidade, incluindo um mapeamento crítico do uso de outros elementos relacionados à qualidade, o que inclui os programas e ferramentas da qualidade.

\subsection{Dificuldades da certificação}

Alguns obstáculos à implantação de sistemas, programas ou mesmo ferramentas da qualidade podem existir e necessitam de especial atenção dos gestores. Muitas empresas que implementaram sistemas de gestão da qualidade, apesar dos esforços, acabaram abandonando-os, principalmente devido à falta de comprometimento da alta gerência, restrições financeiras, culturas inadequadas e excessiva burocracia encontrada no uso e interpretação errônea dos preceitos da norma (HELLSTEN; KLEFSJÖ, 2000; FRANCESCHINI; GALLETO; CECCONI, 2006). Para Tarawneh (2000), as principais dificuldades são: resistência à mudança; baixa capacitação da mão de obra; complexidade de alguns instrumentos de gestão e de processos produtivos da empresa; e necessidade de investimento constante em capacitação e melhorias.
Para Asif et al. (2009), as empresas focam muito o caminho para implementação da norma (processos e práticas), mas ignoram os mecanismos para sua institucionalização, que é o processo de torná-la parte integral e sustentável da organização, incorporando-a efetivamente à sua cultura e estrutura.

Pinto, Carvalho e Ho (2006) destacam como as principais causas do insucesso dos programas de qualidade ISO 9001, do Seis Sigma e da TQM (Total Quality Management) a escassez de recursos financeiros para a implantação e o frágil apoio da direção da empresa. Mattos e Toledo (1998), por sua vez, enfatizam dificuldades relacionadas à gestão e formalização dos custos da qualidade.

Para Corbett, Montes-Sancho e Kirsch (2005), outras dificuldades são os custos consideráveis com auditores e consultores e tempo e esforço demandados dos funcionários e dirigentes. Soma-se a isto o fato de a ISO 9001 ser geralmente o primeiro padrão normativo de gestão adotado pelas empresas, o que as faz ter que desenvolver processos e documentos do estágio zero.

\subsection{Sinergia com outros programas}

Para Carvalho e Miguel (2012), outras normas de gestão de caráter voluntário foram fortemente influenciadas pela ISO 9001, como a ISO 14001 de Gestão Ambiental e a OHSAS 18001 de Saúde e Segurança do Trabalho.

Em decorrência da conscientização popular crescente sobre os danos causados ao meio ambiente e à saúde de comunidades, as organizações estão sendo cada vez mais pressionadas a demonstrar gerenciamento adequado de suas estruturas ambientais, sociais e econômicas (POMBO; MAGRINI, 2008). A opção mundialmente mais utilizada para equacionar as demandas ambientais e também melhorar o desempenho organizacional são os sistemas de gestão ambiental com base na norma ISO 14001, que foi desenvolvido para ser compatível com a ISO 9001 (AVILA; PAIVA, 2006).

González, Sarkis e Adenso-Díaz (2008) salientam que a organização se beneficiará com a implantação deste sistema por meio da redução de custos, melhor atendimento das necessidades dos clientes, gestão de melhorias, melhoria da imagem junto à sociedade, aumento da responsabilidade social, redução do consumo de energia, maior eficiência nos processos, redução de geração de rejeitos, uso de técnicas mais eficientes de tratamento de efluentes líquidos e incremento da vantagem competitiva. Além disso, a cadeia de suprimentos começa a sofrer exigências dos fornecedores e clientes, fazendo com que a questão ambiental seja difundida ao longo de toda ela.

Destaca-se que, para pequenas e médias empresas, o desafio do desenvolvimento e implementação das 
estratégicas ambientais é ainda maior, dadas suas limitações financeiras (DAHLMANN; BRAMMER; MILLINGTON, 2007).

Em contrapartida, estas empresas de porte menor têm elementos que contrabalanceiam a deficiência financeira e facilitam o desenvolvimento de sistemas deste tipo: estrutura organizacional mais horizontalizada; processos mais simples; maior agilidade na tomada de decisão; maior eficácia no fluxo de informações; etc.

Já a norma OHSAS 18001:2007 (Occupational Health and Safety Assessement Series), também desenvolvida para ser compatível com o sistema ISO 9001, fornece requisitos mínimos para os sistemas de gestão de segurança e saúde do trabalho. Ela também se baseia no ciclo PDCA, como as normas ISO 9001 e ISO 14001. Segundo OHSAS 18001 (OCCUPATIONAL..., 2007), os fatores que influenciam mais fortemente o desempenho da gestão da saúde e segurança do trabalho em uma empresa são: nível de detalhes e a complexidade do sistema; porte da organização; cultura da empresa; e natureza dos seus serviços e produtos.

\subsection{Práticas da qualidade}

Behara e Gundersen (2001) concluíram que nem todos os programas e ferramentas da qualidade são igualmente apropriados para todas as organizações. $\mathrm{O}$ nível de qualidade e desempenho da gestão influencia e às vezes define quais deles devem ser utilizados.

Existem vários modelos de Gestão da Qualidade Total (Total Quality Management - TQM) disponíveis, mas alguns construtos são identificados na maioria deles: foco no cliente; liderança e comprometimento da alta gerência; envolvimento e participação da força de trabalho; relacionamento com os fornecedores e parceiros; gestão por processos, gestão por diretrizes; melhoria contínua de processos, produtos e serviços; e análise de fatos e dados relativos à qualidade. Alguns elementos são fundamentais para o sucesso na implementação destes sistemas: estabelecer objetivos claros e factíveis; atribuição de poder; e treinamento dos funcionários no uso das técnicas e ferramentas da TQM (HELLSTEN; KLEFSJÖ, 2000; CALARGE; LIMA, 2001; VALLS, 2004; PINTO; CARVALHO; HO, 2006; FRANCESCHINI; GALLETO; CECCONI, 2006; PINTO; CARVALHO; HO, 2008).

Várias práticas estão associadas à implementação bem-sucedida da gestão da qualidade. A denominação de práticas envolve, neste trabalho, programas e ferramentas da qualidade.

Alguns autores, como Worley e Doolen (2006), Gapp, Fisher e Kobayashi (2008), Pettersen (2009), Godinho Filho e Fernandes (2009), Agostino e Arnaboldi (2011) e Ray e Das (2010), apontam, por exemplo, o Balanced Scorecard (BSC), a produção enxuta (Lean Production), o 5S e o Six Sigma como programas fortemente relacionados à gestão da qualidade.

Já as ferramentas básicas associadas à gestão da qualidade com forte potencial de uso pelos grupos de melhoria na organização são: 5W1H; Brainstorming; Benchmarking; Círculos de Controle da Qualidade; Controle Estatístico do Processo; Diagrama de Ishikawa; e Diagrama de Pareto (EIGELES, 2003; MADU, 2005; SALAHELDIN; ZAIN, 2007; ADEBANJO; ABBAS; MANN, 2010; HENSLEY; UTLEY, 2011; CHAVAN, 2011).

Por outro lado, existe um conjunto de ferramentas avançadas da qualidade, que obviamente geram resultados mais expressivos, porém que exigem maior desenvoltura da empresa: Análise do Modo e Efeito da Falha (Failure Mode and Effect Analysis - FMEA), Desdobramento da Função Qualidade (Quality Function Deployment - QFD) e SERVQUAL (TENG et al., 2006; LADHARI, 2009; MEHRJERDI, 2010). Esta última aplicada a empresas de serviço. O Apêndice 1 traz a definição dessas práticas, que foram encaminhadas, junto ao instrumento de pesquisa, para os respondentes do survey.

\section{Método de pesquisa}

Esta pesquisa é do tipo survey, cujo questionário foi estruturado com base na escala Likert de 5 pontos e enviado por $e$-mail para as 3.951 empresas, certificadas segundo a norma ISO 9001, com cadastro atualizado no banco de dados INMETRO, das quais se obteve um retorno efetivo de 191 questionários respondidos. Suas questões foram elaboradas de forma que não houvesse intervenção direta e influência do pesquisador sobre o pesquisado, conforme preceituam Sampieri, Collado e Lucio (2006).

Foi realizado um teste piloto com o questionário em duas organizações pertencentes ao universo a ser estudado antes de ele ser efetivamente enviado, conforme sugerem Cooper e Schindler (2003). Como resultados deste teste, foram realizadas alterações em algumas poucas questões e fusões de outras.

O questionário continha algumas poucas perguntas abertas e, em sua grande maioria, perguntas fechadas com base na escala Likert, em que as empresas deveriam classificar seu nível de concordância com as questões postas por meio de uma escala de 1 a 5 que representava, respectivamente: discordo totalmente; discordo; indiferente; concordo; e concordo plenamente.

O questionário foi estruturado da seguinte maneira: uma primeira parte caracterizando a empresa (porte, tempo de mercado, principais produtos, etc.); uma segunda parte caracterizando os sistemas certificáveis de gestão; e uma terceira parte investigando os programas e ferramentas da qualidade. 
A tabulação dos dados foi realizada de modo a sistematizar as informações colhidas, agrupando-as de forma que se pudesse trabalhá-las estatisticamente. Utilizando o software Statistica, as informações foram analisadas de modo a traçar um cenário da situação das empresas em relação ao objeto de pesquisa.

\section{Apresentação e análise dos resultados}

As empresas pesquisadas são, em sua maioria, da região Sudeste (65\%) e de pequeno (46\%) e médio porte $(33 \%)$. A amostra foi composta predominantemente por empresas que pertencem à indústria de transformação $(62,8 \%)$, seguida pela indústria de construção $(28,8 \%)$.

Da amostra, 37,91\% conseguiram sua primeira certificação ISO 9001 entre os anos de 2006 e 2009; $35,71 \%$ certificaram no período de 2001 a $2005 ; 17 \%$ conseguiram sua certificação entre os anos de 1996 e 2000; e apenas 9,34\% das empresas certificaram antes de 1995, conforme mostra a Figura 1. Percebe-se um gradativo aumento do número de certificações no decorrer dos anos, seguindo a tendência mundial.

A Figura 2 mostra o investimento feito pelas empresas para conseguir a certificação ISO 9001. Pelos dados, percebe-se que $77 \%$ dos respondentes investiram, no máximo, $\mathrm{R} \$ 50.000,00$ para conseguir sua certificação ISO 9001, e apenas 4,23\% da amostra investiu entre $\mathrm{R} \$ 100.001,00$ a $\mathrm{R} \$ 500.000,00$. Esses resultados estão em consonância com os dados de

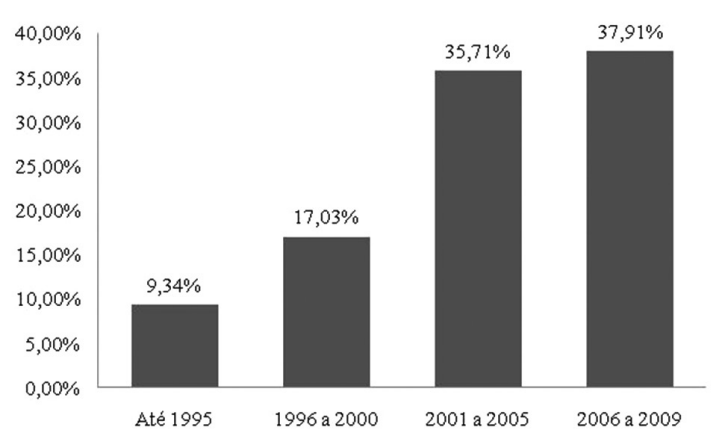

Figura 1. Ano da primeira certificação ISO 9001.

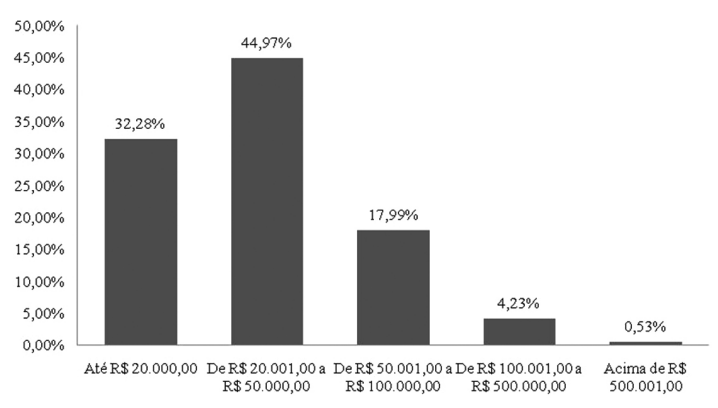

Figura 2. Investimento para a certificação ISO 9001. porte das empresas estudadas, em que apenas 17\% são de grande porte.

Das empresas da amostra, 13,61\% possuem certificação ISO 14001 e 8,38\% possuem certificação OHSAS 18001.

O Apêndice 2 apresenta a síntese da estatística descritiva das questões referentes a motivação, benefícios, dificuldades e grau de utilização de programas e ferramentas da qualidade, apresentando sua média, desvio padrão, moda e mediana. Estas questões serão analisadas nesta parte do artigo.

A implantação e certificação ISO 9001 requer tempo e dedicação dos colaboradores. Aproximadamente metade da amostra implantou o sistema entre 6 e 12 meses (50,5\%), seguido da faixa de 12 a 18 meses com 26,8\%.

Os resultados revelam que os programas e/ou ferramentas (práticas) mais utilizados foram: $5 \mathrm{~S}$ (média 4,03), brainstorming (média 3,72) e diagrama de Ishikawa (média 3,61), todas com mediana 4 e moda 5. Por outro lado, as menos utilizadas foram: Servqual (média 1,46) e QFD (média 2,09), ambas com a moda igual a 1 , ou seja, a maioria das empresas pesquisadas as desconhecem, conforme ilustra a Figura 3.

No caso do Servqual, por ser uma ferramenta aplicada a serviços, o desconhecimento e pouca utilização podem estar associados ao perfil da amostra, que é predominantemente de empresas industriais. No entanto, no caso do QFD o resultado não era esperado, pois esta ferramenta está elencada nas normas TS do setor automobilístico.

As principais motivações para implementação ISO 9001 apontadas pelas empresas foram: melhoria na organização interna (média 4,55), maior eficiência produtiva (média 4,49) e maior confiabilidade na marca da empresa perante consumidores (média 4,39 ), todas essas alternativas tiveram média e moda iguais a 5, ou seja, concordância plena.

Vale destacar que a maioria das motivações apresentadas no instrumento de pesquisa atingiu um grau de concordância elevado (média geral 3,85), conforme ilustra a Figura 4 (ver também dados no Apêndice 2). As exceções foram as alternativas referentes à exigência de regulamentação de algum bloco econômico ou governo externo e a pressão dos competidores, que obtiveram as duas menores médias, respectivamente 2,63 e 2,89, ambas com mediana 3, que é o ponto de neutralidade da escala.

Destaca-se ainda que, no caso da alternativa sobre e a exigência de regulamentação de algum bloco econômico ou governo externo, a moda foi 1, ou seja, maior número de empresas discorda fortemente que essa seja uma motivação para a implementação de programas de qualidade.

As empresas pesquisadas identificaram vários benefícios como fruto da ISO 9001, sendo a média 


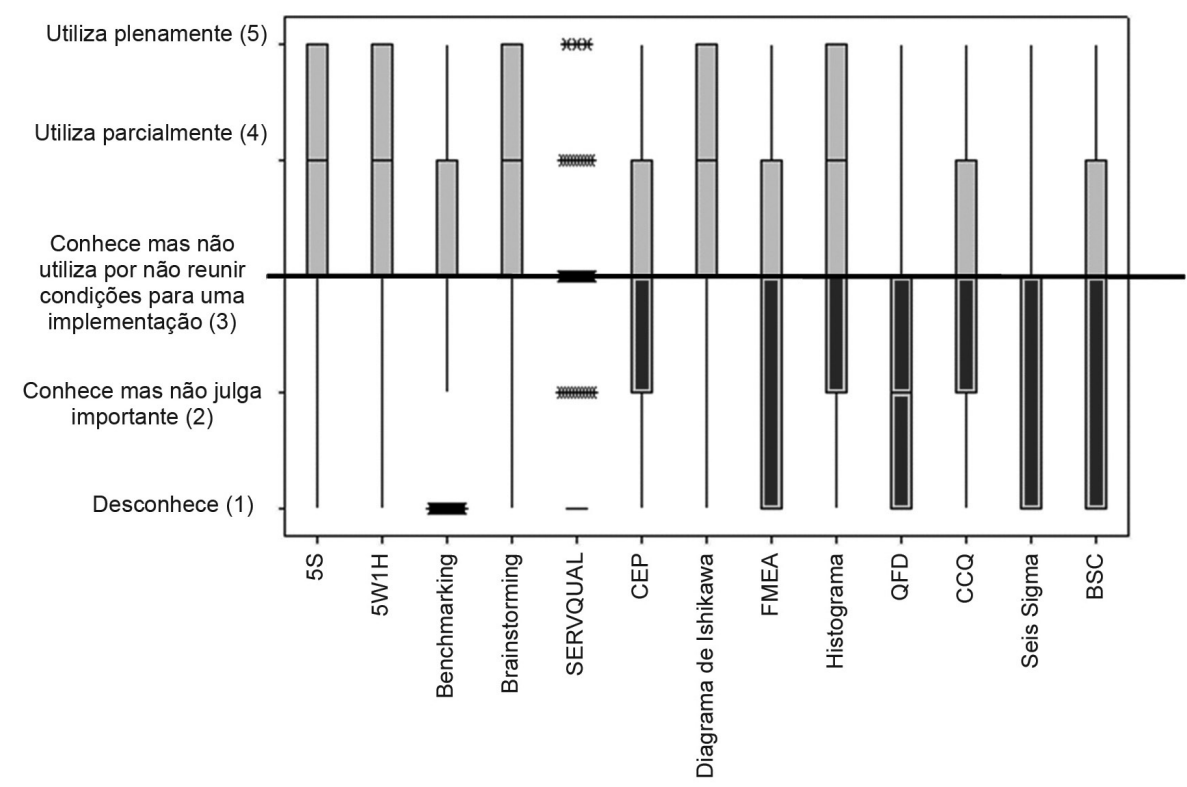

Figura 3. Grau de utilização dos programas e ferramentas da qualidade. Boxplot da amostra para todas as questões do bloco.

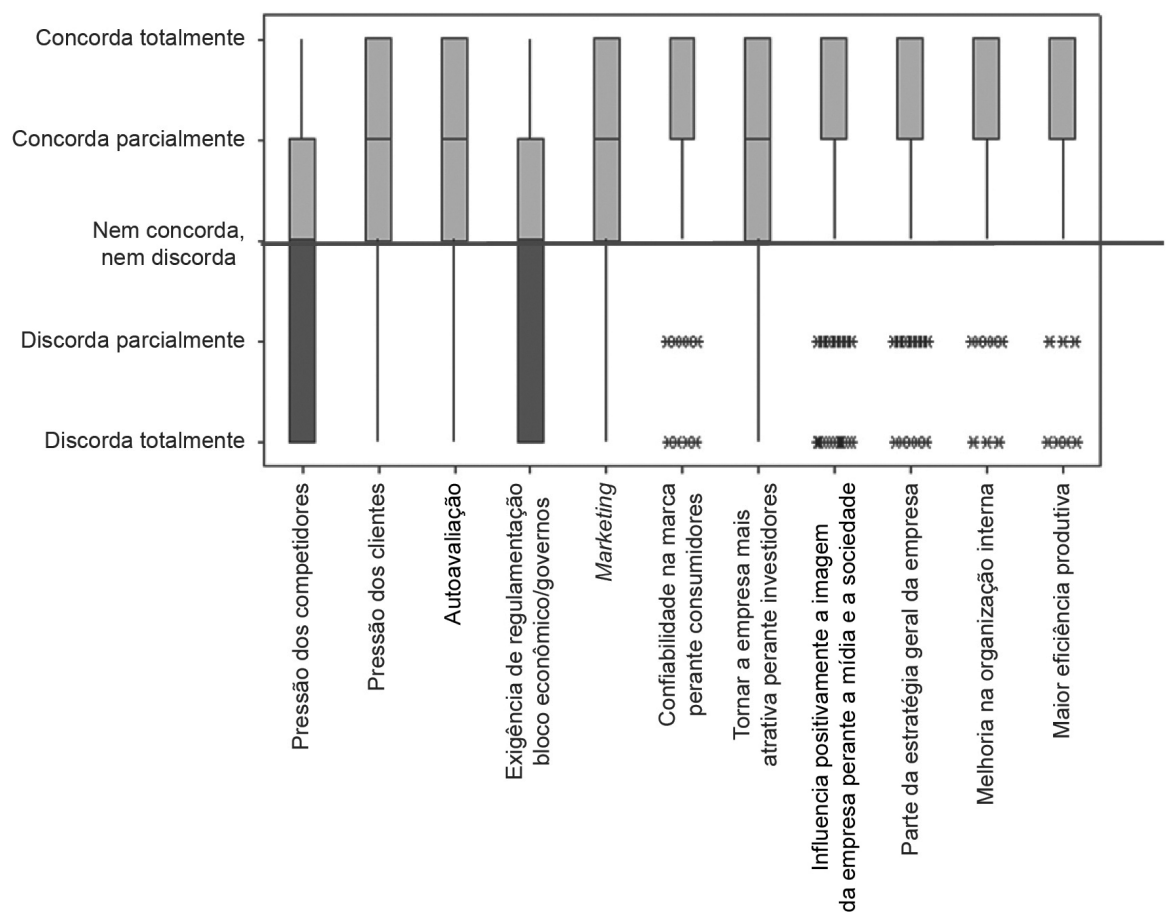

Figura 4. Grau de concordância com relação às motivações para a implementação. Boxplot da amostra para todas as questões do bloco.

geral desse grupo de questões igual a 4,0, conforme ilustra a Figura 5 (ver dados complementares no Apêndice 2). Os benefícios que obtiveram médias mais elevadas foram: melhoria da qualidade nos processos (média 4,58) e maior conscientização dos empregados em relação à qualidade (média 4,55), ambas com moda e mediana iguais a 5. Contudo, além desses dois benefícios, outros seis obtiveram moda e mediana igual a 5 , ou seja, a maioria da amostra concorda plenamente que obteve, além dos dois já elencados, os seguintes benefícios: melhoria na cultura organizacional (média 4,40); melhoria na imagem da empresa (média 4,38); maior visibilidade da empresa junto a clientes e fornecedores (média 


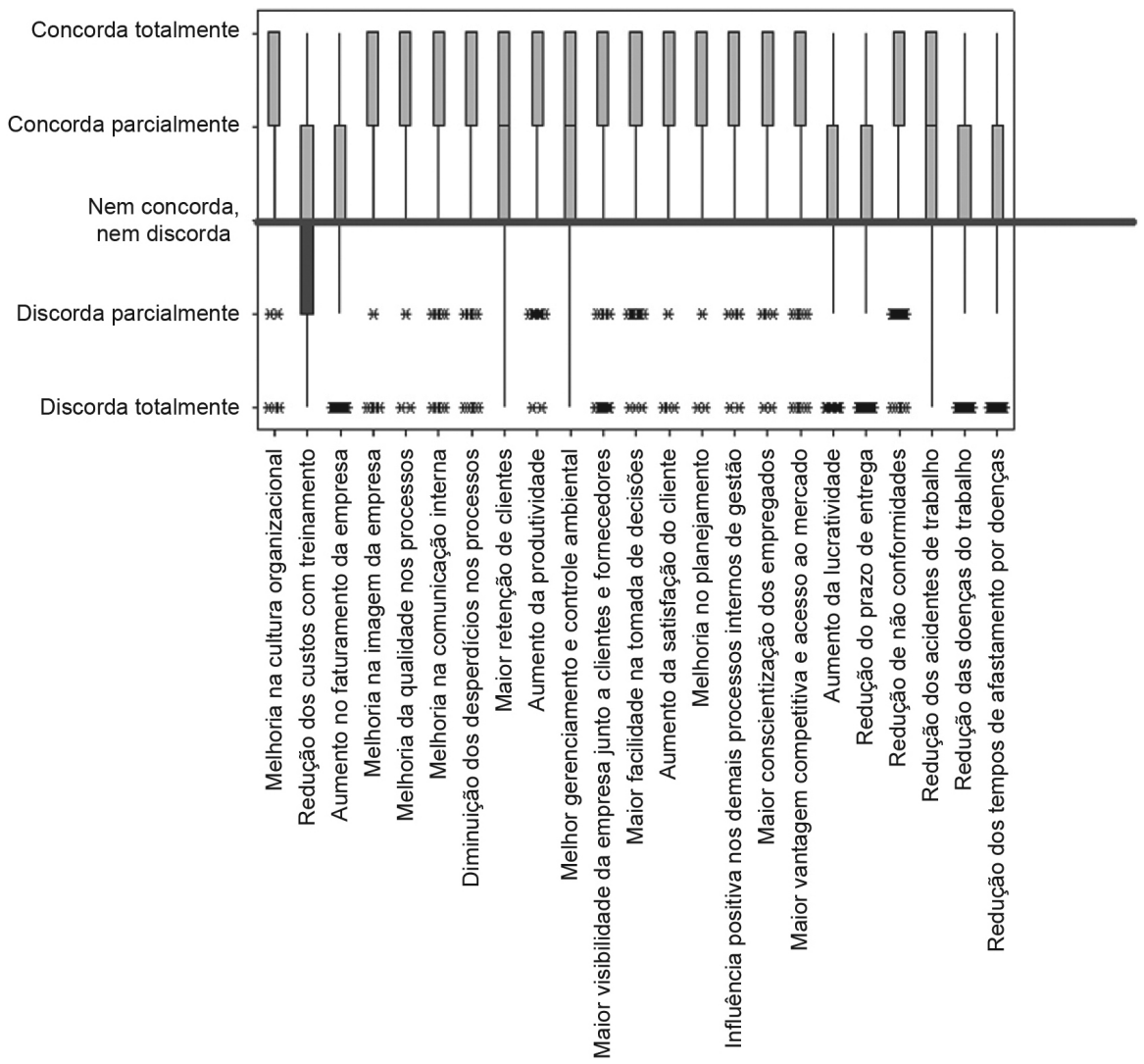

Figura 5. Grau de concordância com relação aos benefícios obtidos. Boxplot da amostra para todas as questões do bloco.

4,32); aumento da satisfação do cliente (média 4,36); melhoria no planejamento (média 4,38); e influência positiva nos demais processos internos de gestão (média 4,38).

O único benefício em que houve leve discordância foi o relacionado à redução dos custos com treinamento (média 2,81), com moda e mediana igual a 3 , ponto de inflexão da escala.

Considerando-se o impacto ISO 9001 nos critérios competitivos, também se observa forte concordância entre as empresas pesquisadas (média geral 4,01), conforme ilustra a Figura 6 (ver dados no Apêndice 2). No entanto, os critérios competitivos qualidade e confiabilidade como já eram de se esperar, destacam-se com moda e mediada igual a 5, enquanto para os critérios flexibilidade, rapidez e custo, a moda e mediana são 4, o que reflete uma concordância parcial.

O resultado do grupo de questões que retrata as dificuldades na implementação da ISO 9001 está sintetizado na Figura 7 (ver também dados no Apêndice 2). Ao contrário das questões de motivação e benefícios, as questões relacionadas às dificuldades obtiveram médias baixas (média geral 2,71), situando-se na região de discordância, o que implica na conclusão de que as empresas não enfrentaram dificuldades significativas no processo de implementação.
A dificuldade mais expressiva estava relacionada à resistência dos funcionários, que obteve média 3,27 e moda e mediana 4, significando uma concordância parcial. Curiosamente, um dos maiores benefícios obtidos foi a maior conscientização dos empregados em relação à qualidade, ou seja, uma vez vencida a resistência dos funcionários, esse aspecto se converte em benefício para a organização.

Para eliminação ou minimização da resistência dos funcionários, pode-se lançar mão dos seguintes elementos: sensibilizar a força de trabalho por meio de palestras e treinamentos; esclarecer e discutir as implicações dos novos procedimentos, seus benefícios e dificuldades tanto para a empresa como para os funcionários; simplificar a linguagem da documentação da qualidade de forma a facilitar o entendimento pelos escalões mais baixos; trabalhar em estreita parceria com o setor de recursos humanos durante a implantação do sistema e premiar o bom desempenho.

Por outro lado, as dificuldades relacionadas ao pouco envolvimento da gerência intermediária, pouco apoio da alta administração, altos custos de implementação e falta de infraestrutura organizacional obtiveram moda 1 , ou seja, as empresas entrevistadas discordam fortemente de que esses aspectos representem dificuldade no processo de implementação. Desta forma, pode-se inferir que houve o apoio tanto da alta administração como da 
média gerência a esse processo, com disponibilização dos recursos necessários de infraestrutura.

\section{Discussão}

Foi feita uma análise para comparar o grau de utilização das ferramentas e programas da qualidade entre empresas que possuem apenas a certificação ISO 9001 e empresas que possuem as certificações ISO 9001, ISO 14001 e OHSAS 18001, simultaneamente. A Figura 8 traz a comparação entre as médias.

$\mathrm{O}$ estudo realizado mostra que as empresas que possuem as três certificações (ISO 9001, ISO 14001 e OHSAS 18001) utilizam as ferramentas e programas

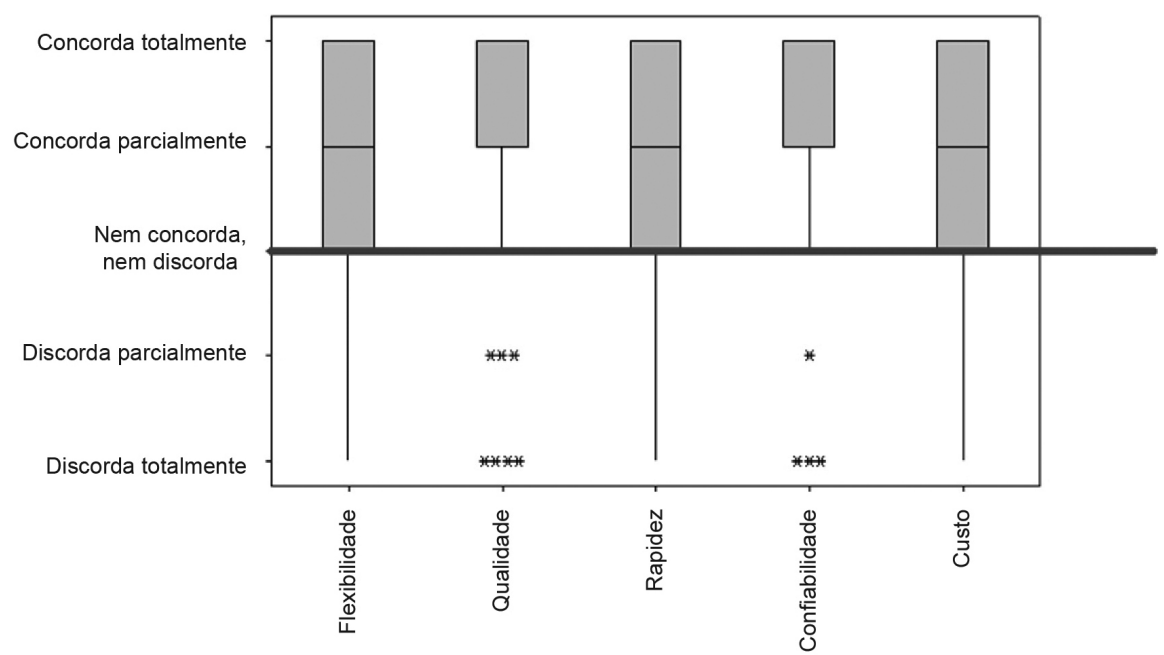

Figura 6. Impacto da ISO 9001 sobre os critérios competitivos. Boxplot da amostra para todas as questões do bloco.

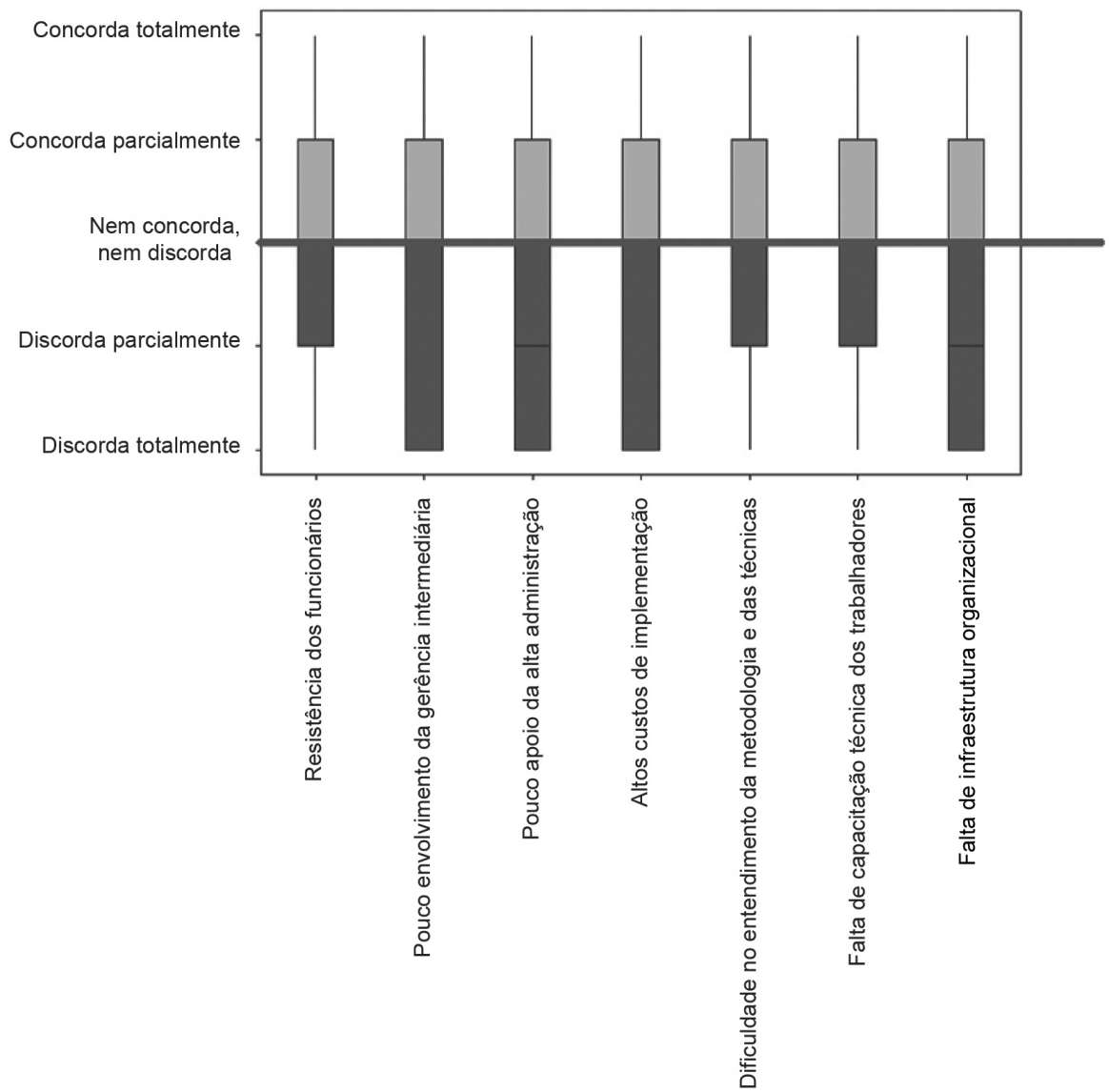

Figura 7. Dificuldades no processo de implementação. Boxplot da amostra para todas as questões do bloco. 


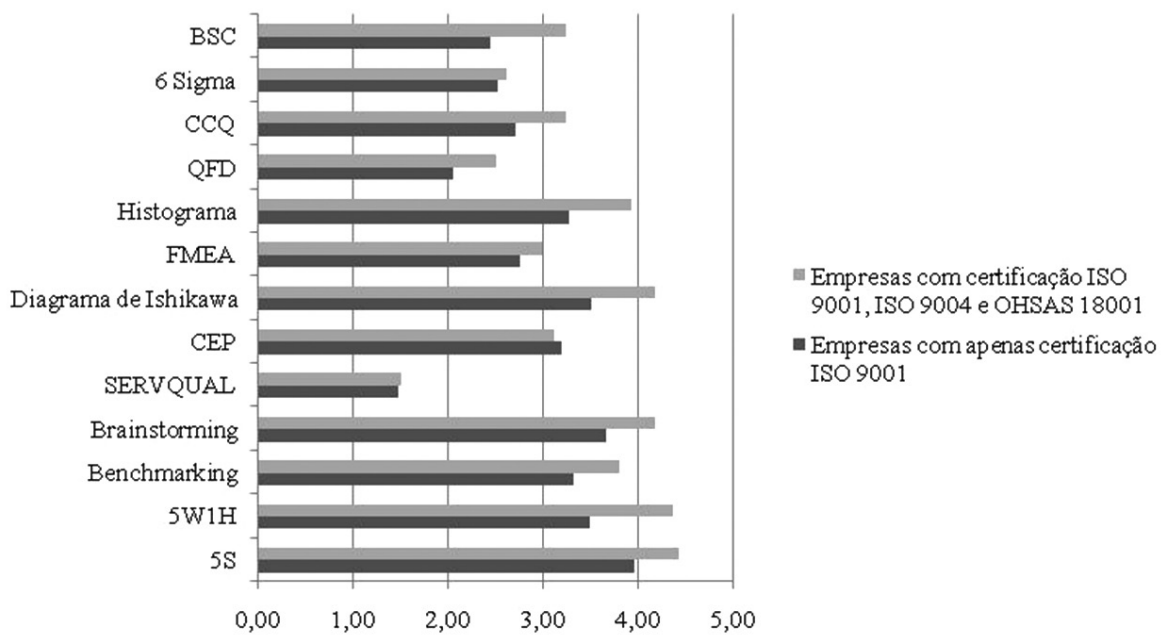

Figura 8. Utilização das práticas da qualidade com foco em outros sistemas.

da qualidade em maior grau comparado com as que possuem apenas certificação ISO 9001. Somente a ferramenta Controle Estatístico do Processo teve média maior nas empresas com apenas a certificação ISO 9001, comparada com a de empresas que possuem as três certificações. Ainda assim, com uma pequena diferença.

Pode-se dizer que esse fenômeno ocorre devido ao fato de que, na maioria dos casos, as empresas com as três certificações são empresas de maior porte, com mais capital para investimento em treinamentos e consultoria para a implantação das ISO 9001, dos programas e das ferramentas da qualidade.

Quando se comparam os resultados desta pesquisa com os do estudo de Pinto, Carvalho e Ho (2006), cujo foco eram empresas de grande porte, observa-se que a incidência de certificação ISO 14001 era bem superior $(39,4 \%)$, contra $13,6 \%$ desta pesquisa. Já no que concerne à certificação OHSAS 18001, o dado é bem mais próximo: $9,1 \%$ daquela, contra $8,38 \%$ da atual pesquisa.

Também se observou, por meio do teste quiquadrado, que as empresas que têm ISO 14001 utilizam mais as ferramentas $5 \mathrm{~W} 1 \mathrm{H}(\mathrm{p}$-value $=0,011)$ e diagrama de Ishikawa ( $p$-value $=0,047$ ) do que as que não têm esse certificado, para um grau de confiança de $95 \%$. Além disso, as empresas que têm certificação OHSAS 18001 utilizam mais as ferramentas $5 \mathrm{~W} 1 \mathrm{H}$ ( $\mathrm{p}$-value $=0,006)$, benchmarking $(\mathrm{p}$-value $=0,015)$ e histograma $(\mathrm{p}$-value $=0,015) \mathrm{do}$ que as que não têm. Nas demais ferramentas, não houve diferença significativa.

No presente estudo, foi utilizado o software Statistica para verificar as correlações existentes entre as questões/empresas ao nível de 5\%. As correlações foram organizadas em uma matriz e aquelas estatisticamente significativas (coeficiente de correlação linear de no mínimo 0,65 ) foram analisadas. A matriz completa não pode ser apresentada neste texto porque seu tamanho é incompatível com o espaço disponível para publicação. Contudo, a Tabela 1 mostra as correlações significativas de acordo com a proposta do trabalho.

O grau de utilização das ferramentas Brainstorming e Benchmarking se mostraram bastante vinculadas. Essas ferramentas, geralmente, são utilizadas em conjunto nas empresas. Pode-se utilizar o Brainstorming para a geração de ideias com o intuito de definir o foco do Benchmarking, que será aplicado, ou também pode ser utilizado, após o Benchmarking como busca de possíveis soluções e ideias. Além disso, possuem baixo custo de implantação e poucas horas de treinamento dos colaboradores são necessárias.

A implantação ISO 9001 traz muitos benefícios para a instituição que se propõe a desenvolver seus conceitos e funções. Os respondentes desta pesquisa identificaram que a motivação "Melhoria na eficiência produtiva" está altamente relacionada a "Melhoria na organização interna" e vice-versa. Com a padronização dos processos técnicos e administrativos e com a definição de responsabilidades, as empresas tornam-se mais organizadas internamente, e, desse modo, geram-se menos retrabalhos e desperdícios, aumentando a produtividade e a qualidade de produtos e serviços, ou seja, aumentando a eficiência produtiva.

Os benefícios com a implementação da ISO 9001 mostraram elevada correlação positiva entre si (ver Tabela 1), ou seja, quando um benefício era constatado outro benefício era sentido.

Contudo destaca-se a correlação de 0,92 entre o benefício "Redução das doenças do trabalho" com "Redução dos tempos de afastamento por doenças". Verificou-se que a diminuição das enfermidades ocupacionais, muito provavelmente em função de 
Tabela 1. Correlações significativas.

\begin{tabular}{|c|c|c|}
\hline Ferramenta & Ferramenta & $\mathbf{p}$ \\
\hline Benchmarking & Brainstorming & \multirow{2}{*}{0,69} \\
\hline Motivação & Motivação & \\
\hline Maior eficiência produtiva & Melhoria na organização interna & \multirow{2}{*}{0,84} \\
\hline Benefício & Benefício & \\
\hline Melhoria da qualidade nos processos & Melhoria na cultura organizacional & 0,65 \\
\hline Aumento da lucratividade & Aumento no faturamento da empresa & 0,67 \\
\hline $\begin{array}{l}\text { Maior visibilidade da empresa junto a clientes e } \\
\text { fornecedores }\end{array}$ & Melhoria na imagem da empresa & 0,67 \\
\hline Aumento da satisfação do cliente & Melhoria na imagem da empresa & 0,68 \\
\hline Melhoria na comunicação interna & Melhoria da qualidade nos processos & 0,68 \\
\hline Maior vantagem competitiva e acesso ao mercado & Maior retenção de clientes & 0,69 \\
\hline Aumento da satisfação do cliente & Maior facilidade na tomada de decisões & 0,66 \\
\hline Melhoria no planejamento & Maior facilidade na tomada de decisões & 0,70 \\
\hline Melhoria no planejamento & Aumento da satisfação do cliente & 0,69 \\
\hline Confiabilidade de produtos e processos & Aumento da satisfação do cliente & 0,65 \\
\hline Redução do prazo de entrega & Aumento da lucratividade & 0,69 \\
\hline Rapidez no lead time de produção e/ou na entrega & Aumento da lucratividade & 0,65 \\
\hline Rapidez no lead time de produção e/ou na entrega & Redução do prazo de entrega & 0,69 \\
\hline Redução das doenças do trabalho & Redução dos acidentes de trabalho & 0,82 \\
\hline Redução dos tempos de afastamento por doenças & Redução dos acidentes de trabalho & 0,76 \\
\hline Redução dos tempos de afastamento por doenças & Redução das doenças do trabalho & 0,92 \\
\hline Rapidez no lead time de produção e/ou na entrega & $\begin{array}{l}\text { Flexibilidade da produção em relação a prazos, local } \\
\text { de entrega, composição do pedido, etc. }\end{array}$ & 0,70 \\
\hline Confiabilidade de produtos e processos & Qualidade dos bens e serviços fornecidos & 0,66 \\
\hline
\end{tabular}

melhores condições de trabalho proporcionadas pelo SGQ, está altamente relacionada com a diminuição dos afastamentos. Isto impacta positivamente o moral da força de trabalho e, consequentemente, a produtividade da empresa.

\section{Conclusão}

Este trabalho permitiu avançar no mapeamento e compreensão da realidade das organizações brasileiras certificadas segundo a norma ISO 9001. Neste sentido, o estudo atualiza pesquisas anteriores, bem como permite traçar um panorama do uso deste tipo de sistema em empresas brasileiras.

Observa-se que, apesar de os benefícios serem exaltados pelas empresas pesquisadas e as dificuldades minimizadas, o grau de utilização de programas e ferramentas ainda está bem aquém do que apontam as pesquisas com dados de grandes empresas nacionais e internacionais.

$\mathrm{O}$ panorama traçado pode dar suporte às organizações que pretendem desenvolver este tipo de sistema e, com isso, fazer com que elas evitem cometer os mesmos erros que suas predecessoras. Também são dados que certamente motivarão muitos empresários, consultores e pesquisadores no desenvolvimento destes sistemas, programas e ferramentas em função do panorama positivo aqui apresentado.
Outro aspecto importante é que não se verifica a efetiva utilização conjunta dos sistemas gestão ISO 9001, ISO 14001 e OHSAS 18001, dado que poucas são as empresas da amostra que as possuem concomitantemente.

\section{Referências}

ADEBANJO, D.; ABBAS, A.; MANN, R. An investigation of the adoption and implementation of benchmarking. International Journal of Operations \& Production Management, v. 30, n. 11, p. 1140-1169, 2010. http:// dx.doi.org/10.1108/01443571011087369

AGOSTINO, D.; ARNABOLDI, M. How the BSC implementation process shapes its outcome. International Journal of Productivity and Performance Management, v. 60, n. 2, p. 99-114, 2011. http://dx.doi. org/10.1108/17410401111101458

AL-RAWAHI, A. M. S.; BASHIR, H. A. On the implementation of ISO 9001:2000: a comparative investigation. The TQM Journal, v. 23, n. 6, p. 673-687, 2009. http:// dx.doi.org/10.1108/17542731111175275

ANDERSON, S. W.; DALY, J. D.; JOHNSON, M. F. Why firms seek ISO 9000 certification: regulatory compliance or competitive advantage? Production and Operations Management, v. 8, n. 1, p. 28-43, 1999. http://dx.doi. org/10.1111/j.1937-5956.1999.tb00059.x

ASIF, M. et al. Why quality management programs fail: a strategic and operations management perspective. 
International Journal of Quality \& Reliability Management, v. 26, n. 8, p. 778-794, 2009. http:// dx.doi.org/10.1108/02656710910984165

AVILA, G. J.; PAIVA, E. L. Processos operacionais e resultados de empresas brasileiras após a certificação ambiental ISO 14001. Gestão \& Produção, v. 13, n. 3, p. 475-487, 2006. http://dx.doi.org/10.1590/ S0104-530X2006000300010

BATTIKHA, M. G. Quality management practice in highway construction. International Journal of Quality \& Reliability Management, v. 20, n. 5, p. 532-550, 2003. http://dx.doi.org/10.1108/02656710310476516

BEATTIE, K. R.; SOHAL, A. S. Implementing ISO 9000: a study of its benefits among Australian organizations. Total Quality Management, v. 10, n. 1, p. 95-106, 1999. http://dx.doi.org/10.1080/0954412998090

BEHARA, R. S.; GUNDERSEN, D. E. Analysis of quality management practices in services. International Journal of Quality \& Reliability Management, v. 18, n. 6 , p. 584-603, 2001. http://dx.doi. org/10.1108/02656710110393501

CALARGE, F. A.; LIMA, P. C. Da abordagem do TQM (Total Quality Management) Ao GQM (Global Quality Management): a inserção e utilização da metodologia do projeto axiomático no desenvolvimento de modelos de gestão sistêmica da qualidade. Gestão \& Produção, v. 8 , n. 2, p. 196-213, 2001. http://dx.doi.org/10.1016/j. foodcont.2008.04.008

CARVALHO, M. M.; MIGUEL, P. A. C. Qualidade e Sustentabilidade. In: CARVALHO, M. M.; PALADINI, E. P. Gestão da Qualidade: teoria e casos. 2. ed. Rio de Janeiro: Editora Campus, 2012.

CHAVAN, M. Quality management and quality care. Asian Journal on Quality, v. 12, n. 1, p. 91-112, 2011. http:// dx.doi.org/10.1108/15982681111140570

COOPER, R. D.; SCHINDLER, P. S. Método de pesquisa em administração. 7. ed. Bookman, 2003.

CORBETT, C. J. Global diffusion of ISO 9000 certification through supply chains. Manufacturing \& Service Operations Management, v. 8, n. 4, p. 330-350, 2005. http://dx.doi.org/10.1287/msom.1060.0120

CORBETT, C. J.; MONTES-SANCHO, M. J.; KIRSCH, D. A. The financial impact of ISO 9000 certification in the United States: an empirical analysis. Management Science, v. 51, n. 7, p. 1046-1059, 2005. http://dx.doi. org/10.1287/mnsc. 1040.0358

CORREIA, L. C. C.; MELO, M. A. N.; MEDEIROS, D. D. Modelo de diagnóstico e implementação de um sistema de gestão da qualidade: estudo de um caso. Produção, v. 16, n. 1, p. 111-125, 2006. http://dx.doi.org/10.1590/ S0103-65132006000100010

DAHLMANN, F.; BRAMMER, S.; MILLINGTON, A. Environmental management in the United Kingdom: new survey evidence. Management Decision, v. 46, n. 2, p. 264-283, 2007. http://dx.doi. org/10.1108/00251740810854159

DOUGLAS, A.; COLEMAN, S.; ODDY, R. The case for ISO 9000. The TQM Magazine. v. 15, n. 5, p. 316-324, 2003. http://dx.doi. org/10.1108/09544780310487712
EIGELES, D. Facilitating shared vision in the organization. Journal of European Industrial Training, v. 27, n. 5, p. 208-219, 2003. http://dx.doi. org/10.1108/03090590310469597

FENG, M.; TERZIOVSKI, M.; SAMSON, D. Relationship of ISO 9001:2000 quality system certification with operational and business performance. Journal of Manufacturing Technology Management, v. 19, n. 1, p. 22-37, 2008. http://dx.doi. org/10.1108/17410380810843435

FRANCESCHINI, F.; GALLETO, M.; CECCONI, P. A worldwide analysis of ISO 9000 standard diffusion, considerations and future development. Benchmarking: An International Journal, v. 13, n. 4, p. 523-541, 2006.

GALBINSKI, J. ISO publica nova edição da ISO 9001. Banas Qualidade, n. 199, p. 9, 2008.

GAPP, R.; FISHER, R.; KOBAYASHI, K. Implementing 5S: An integrated management system. Management Decision, v. 46, n. 4, p. 565-579, 2008. http://dx.doi. org/10.1108/00251740810865067

GODINHO FILHO, M.; FERNANDES, F. C. F. Manufatura Enxuta: uma revisão que classifica e analisa trabalhos apontando perspectivas de pesquisas futuras. Gestão \& Produção, v. 11, n. 1, p. 1-19, 2009. http://dx.doi. org/10.1590/S0104-530X2004000100002

GONZÁLEZ, P.; SARKIS, J.; ADENSO-DÍAZ, B. Environmental management system certification and its influence on corporate practices. International Journal of Operations \& Production Management, v. 28 , n. 11 , p. 1021-1041, 2008. http://dx.doi. org/10.1108/01443570810910179

HELLSTEN, U.; KLEFSJÖ, B. TQM as a management system consisting of value, techniques and tools. The TQM Magazine, v. 12, n. 4, p. 238-244, 2000. http:// dx.doi.org/10.1108/09544780010325822

HENSLEY, R. L.; UTLEY, J. S. Using reliability tools in service operations. International Journal of Quality \& Reliability Management, v. 28, n. 5, p. 587-598, 2011. http://dx.doi.org/10.1108/02656711111132599

HUARNG, F.; HORNG, C.; CHEN, C. A study of ISO 9000 process, motivation and performance. Total Quality Management, v. 10, n. 7, p. 1009-1025, 1995. http:// dx.doi.org/10.1080/0954412997190

INTERNATIONAL ORGANIZATION FOR STANDARDIZATION - ISO. ISO 9000: Sistema de gestão da qualidade: fundamentos e vocabulário. ISO, 2008.

KUMAR, V. et al. Impact of TQM on company's performance. International Journal of Quality \& Reliability Management, v. 26, n. 1, p. 23-37, p. 2009.

LADHARI, R. A review of twenty years of servqual research. International Journal of Quality and Services Sciences, v. 1, n. 2, p. 172-198, 2009. http://dx.doi. org/10.1108/17566690910971445

LAGROSEN, S.; LAGROSEN, Y. Quality configurations: a contingency approach to quality management. International Journal of Quality \& Reliability Management, v. 20, n. 7, p. 759-773, 2003. http:// dx.doi.org/10.1108/02656710310491203

LAKHAL, L.; PASIN, F.; LIMAM, M. Quality management practices and their impact on performance. 
International Journal of Quality \& Reliability Management, v. 23, n. 6, p. 625-646, 2006. http:// dx.doi.org/10.1108/02656710610672461

LEE, C. Y.; ZHOU, X. Quality management and manufacturing strategies in China. International Journal of Quality \& Reliability Management, v. 17 , n. 8 , p. 876-899, 2000. http://dx.doi. org/10.1108/02656710010325101

LIMA, M. A. M.; RESENDE, M.; HASECNCLEVER, L. Quality certification and Performance of Brazilian firms: an empirical study. International Journal of Production Economics, v. 66, n. 2, p. 143-147, 2000. http://dx.doi.org/10.1016/S0925-5273(99)00118-8

LO, L. K.; CHANG, D. S. The difference in the perceived benefits between firms that maintain ISO certification and those that do not. International Journal of Production Research, v. 48, n. 5, p. 1881-1897, 2007. http://dx.doi. org/10.1080/00207540600733709

MACHADO, J. A.; ROTONDARO, R. G. Mensuração da qualidade de serviços: um estudo de caso na indústria de serviços bancários. Gestão \& Produção, v.10, n. 2, p. 217-230, 2003. http://dx.doi.org/10.1590/ S0104-530X2003000200007

MADU, C. N. Strategic value of reliability and maintainability management. International Journal of Quality \& Reliability Managemen, v. 22, n. 3, p. 317-328, 2005. http://dx.doi.org/10.1108/02656710510582516

MATTOS, J. C.; TOLEDO, J. C. Custos da qualidade: diagnóstico nas empresas com certificação ISO 9000. Gestão \& Produção, v. 5, n. 3, p. 312-324, 1998. http://dx.doi.org/10.1590/S0104-530X1998000300011

MEHRJERDI, Y. Z. Quality function deployment and its extensions. International Journal of Quality \& Reliability Management, v. 27, n. 6, p. 616-640, 2010. http://dx.doi.org/10.1108/02656711011054524

MOTWANI, J.; KUMAR, A.; CHENG, C. H. A roadmap to implementing ISO 9000 . International Journal of Quality Reliability Management, v. 13, n. 1, p. $72-83,1996$. http://dx.doi. org/10.1108/02656719610108332

NAIR, A.; PRAJOGO, D. Internalisation of ISO 9000 standards: the antecedent role of functionalist and institutionalist drivers and performance implications. International Journal of Production Research, v. 47, n. 16, p. 4545-4568, 2009. http://dx.doi. org/10.1080/00207540701871069

OCCUPATIONAL HEALTH AND SAFETY ASSESMENT SERIES. OHSAS 18001: Sistemas de gestão da segurança e saúde no trabalho: requisitos. OHSAS, 2007.

PETTERSEN, J. Defining lean production. The TQM Journal, v.21, n. 2, p. 127-142. 2009. http://dx.doi. org/10.1108/17542730910938137

PINTO, S. H. B.; CARVALHO, M. M.; HO, L. L. Main quality programs characteristics in large size Brazilian companies. International Journal of Quality and Reliability Management, v. 25, n. 3, p. 276 - 291, 2008. http://dx.doi.org/10.1108/02656710810854287

PINTO, S. H. B.; CARVALHO, M. M.; HO, L. L. Implementação de programas de qualidade: um survey em empresas de grande porte no Brasil. Gestão \&
Produção, v. 13, n. 2, p. 191-203, 2006. http://dx.doi. org/10.1590/S0104-530X2006000200003

POMBO, F. R.; MAGRINI, A. Panorama de aplicação da norma ISO 14001 no Brasil. Gestão \& Produção, v. 15 , n. 1, p. 1-10, 2008. http://dx.doi.org/10.1590/ S0104-530X2008000100002

PSOMAS, E. L.; FOTOPOULOS, C. V.; KAFETZOPOULOS, D. P. Core process management practices, quality tools and quality improvement in ISO 9001 certified manufacturing companies. Business Process Management Journal, v. 17, n. 3, p. 437-460, 2011. http://dx.doi.org/10.1108/14637151111136360

RAY, S.; DAS, P. Six Sigma project selection methodology. International Journal of Lean Six Sigma, v. 1, n. 4, 293-309, 2010. http://dx.doi. org/10.1108/20401461011096078

RAYNER, P.; PORTER, L. BS5750/ISO 9000: the experience of small and medium sized businesses. International Journal of Quality Reliability Management, v. 8, n. 6, p. 16-28, 1991.

SALAHELDIN, S. I.; ZAIN, M. How quality control circles enhance work safety: a case study. The TQM Magazine, v. 19, n. 3, p. 229-244, 2007. http://dx.doi. org/10.1108/09544780710745658

SAMPAIO, P.; SARAIVA, P.; RODRIGUES, A. G. ISO 9001 certification research: questions, answers and approaches. International Journal of Quality \& Reliability Management, v. 26, n. 1, p. 38-58, 2009.

SAMPIERI, R. H.; COLLADO, C. F.; LUCIO, P. B. Metodologia de pesquisa. 3. ed. São Paulo: McGrawHill, 2006. http://dx.doi.org/10.1108/02656710910924161

SCOTT, B. S.; WILCOCK, A. E.; KANETKAR, V. A survey of structured continuous improvement programs in the Canadian food sector. Food Control, v. 20, n. 3, 209-217, 2009. http://dx.doi.org/10.1590/ S0104-530X2001000200007

SHIH, L. H.; HUARNG, F.; LIN, B. ISO in Taiwan: a survey. Total Quality Management, v. 7, n. 6, p. 681-690, 1996. http://dx.doi.org/10.1080/09544129610568

SLACK, N.; CHAMBERS, S.; JOHNSTON, R. Administração da produção. São Paulo: Atlas, 2002.

TARAWNEH, M. ISO 9000: Benefits and Difficulties: An Applied Study on Jordanian Industrial Companies. Dirasat: Management Science, v. 27, n. 2, 2000.

TENG, S. G. et al. Implementing FMEA in a collaborative supply chain environment. International Journal of Quality \& Reliability Management, v. 23, n. 2, p. 179-196, 2006. http://dx.doi. org/10.1108/02656710610640943

TERZIOVSKI, M.; SOHAL, A. S. The adoption of continuous improvement and innovation strategies in Australian manufacturing firms. Technovation, v. 20, p. 539-550, 2000. http://dx.doi.org/10.1016/ S0166-4972(99)00173-X

UENO, A. Which management practices are contributory to service quality? International Journal of Quality \& Reliability Management, v. 25, n. 6, p. 585-603, 2008. http://dx.doi.org/10.1108/02656710810881890

VALLS, V. M. Gestão da Qualidade em serviço de informação no Brasil: estabelecimento de um modelo de referência baseado nas diretrizes da NBR 
ISO 9001. 2005. 247 f. Tese (Doutorado)-Escola de Comunicação e Artes, Universidade de São Paulo, São Paulo, 2005.

VALLS, V. M. O enfoque por processos da NBR ISO 9001 e sua aplicação nos serviços de informação. Ciência da Informação, v. 33, n. 2, p. 172-178, 2004. http://dx.doi. org/10.1590/S0100-19652004000200018

VAN DER WIELE, T.; BROWN, A. ISO 9000 series experiences in small and medium sized enterprises. Total Quality Management, v. 8, n. 2-3, p. 300-304, 1997. http://dx.doi.org/10.1080/09544129710297

VLOEBERGHS, D.; BELLENS, J. Implementing the ISO 9000 standards in Belgium. Quality Progress, v. 29, n. 6, p. 43-48, 1996.

WHITE, G. R. T. et al. The implementation of a quality management system in the not-for-profit sector. The
TQM Magazine, v. 21, n. 3, p. 273-283, 2009. http:// dx.doi.org/10.1108/17542730910953040

WORLEY, J. M.; DOOLEN, T. L. The role of communication and management support in a lean manufacturing implementation. Management Decision, v. 44, p. 228-245, 2006. http://dx.doi. org/10.1108/00251740610650210

XAVIER, G. G. Avaliação de programas de qualidade mediante implantação da ISO 9000. Gestão \& Produção, v. 2, n. 2, p. 162-172, 1995. http://dx.doi.org/10.1590/ S0104-530X1995000200004

$\mathrm{ZU}, \mathrm{X}$. Infrastructure and core quality management practices: how do they affect quality? International Journal of Quality \& Reliability Management, v. 26, n. 2, p. 129-49, 2009. http://dx.doi. org/10.1108/02656710910928789 
Apêndice 1. Definição das práticas investigadas.

\begin{tabular}{|c|c|}
\hline \multicolumn{2}{|r|}{ Práticas Definição } \\
\hline $5 S$ & $\begin{array}{l}\text { Seiri, Seiton, Seiso, Seiketsu e Shitsuke, de origem japonesa ou em português Descarte, Arrumação, } \\
\text { Limpeza, Saúde e Disciplina. Tem como objetivos a diminuição de desperdícios e custos e aumento } \\
\text { da produtividade baseado na melhoria da qualidade de vida dos funcionários. }\end{array}$ \\
\hline $5 \mathrm{~W} 1 \mathrm{H}$ ou $5 \mathrm{~W} 2 \mathrm{H}$ & $\begin{array}{l}\text { Trata-se de uma ferramenta que auxilia na estruturação de planos de ação a partir de questões- } \\
\text { chave (O que? Quem? Quando? Onde? Por que? e Como?). Já a 5W2H acrescenta a questão } \\
\text { Quanto? Enfatizando custo da ação. }\end{array}$ \\
\hline $\begin{array}{l}\text { Análise do modo e } \\
\text { do efeito das falhas } \\
\text { (FMEA) }\end{array}$ & $\begin{array}{l}\text { É um processo sistemático e documentado para avaliação e redução de riscos de falhas em projetos } \\
\text { e processos. Seu objetivo é identificar, definir, priorizar e reduzir os potenciais de falhas o mais cedo } \\
\text { possível, diminuindo as chances de sua ocorrência tanto nos clientes internos como externos. }\end{array}$ \\
\hline Benhchmarking & $\begin{array}{l}\text { É um processo contínuo e sistemático para avaliar produtos, serviços e processos em organizações } \\
\text { que são reconhecidas como possuidoras das melhores práticas, com a finalidade de servir de } \\
\text { referência para organizações menos avançadas. }\end{array}$ \\
\hline Brainstorming & $\begin{array}{l}\text { É um processo de grupo em que os indivíduos emitem ideias de forma livre, em grande } \\
\text { quantidade, sem críticas e no menor espaço de tempo possível. }\end{array}$ \\
\hline Check List & $\begin{array}{l}\text { É um processo utilizado para colher dados baseados em observações amostrais com o } \\
\text { objetivo de verificar com que frequência ocorre um evento ao longo de um período de tempo } \\
\text { determinado. }\end{array}$ \\
\hline $\begin{array}{l}\text { Controle Estatístico } \\
\text { do Processo (CEP) }\end{array}$ & $\begin{array}{l}\text { Controla a variação da média e desvio padrão de uma determinada grandeza, utilizando as cartas } \\
\text { de controle. Objetiva manter os processos dentro dos limites estabelecidos. }\end{array}$ \\
\hline $\begin{array}{l}\text { Desdobramento } \\
\text { da função da } \\
\text { qualidade (QFD) }\end{array}$ & $\begin{array}{l}\text { Tem por objetivo auxiliar o time de desenvolvimento a incorporar no projeto as reais necessidades } \\
\text { dos clientes. Por meio de um conjunto de matrizes, parte-se dos requisitos expostos pelos clientes } \\
\text { e realiza-se um processo de "desdobramento", transformando-os em especificações técnicas do } \\
\text { produto. }\end{array}$ \\
\hline $\begin{array}{l}\text { Diagrama de } \\
\text { Ishikawa }\end{array}$ & $\begin{array}{l}\text { É uma representação gráfica que permite a organização de informações por semelhança a partir } \\
\text { de seis eixos principais (método, material, máquinas, meio ambiente, mão,de,obra e medição), } \\
\text { possibilitando a identificação das possíveis causas de um determinado problema ou efeito, de } \\
\text { forma específica e direcionada. }\end{array}$ \\
\hline Fluxograma & $\begin{array}{l}\text { Representa a sequência de atividades e processos, demonstram o fluxo dessas ações e permitem a } \\
\text { identificação de problemas e qual a sua origem. }\end{array}$ \\
\hline Gráfico de Pareto & $\begin{array}{l}\text { Ferramenta gráfica e estatística que organiza e identifica os dados de acordo com suas prioridades, } \\
\text { por exemplo, pela decrescente ordem de frequência. }\end{array}$ \\
\hline Histograma & $\begin{array}{l}\text { O histograma é uma ferramenta estatística que, em forma de gráfico de barras, ilustra a distribuição de } \\
\text { frequência. }\end{array}$ \\
\hline Poka Yoke & $\begin{array}{l}\text { Objetiva a minimização de erros por meio de sistematização de mecanismos simples de prevenção. } \\
\text { Tem o significado "à prova de erros em português". }\end{array}$ \\
\hline ServQual & $\begin{array}{l}\text { Questionário composto por } 22 \text { perguntas que pretendem medir o desempenho da organização em } 5 \\
\text { dimensões (Tangibilidade, Confiabilidade/Credibilidade, Receptividade, Garantia e Empatia), em dois } \\
\text { eixos principais: percepção e expectativa. É no gap entre estes dois elementos que deve se centrar a } \\
\text { atenção dos gestores (LADHARI, 2009; UENO, 2008). }\end{array}$ \\
\hline Setup rápido & $\begin{array}{l}\text { É uma prática utilizada para reduzir o tempo de troca de ferramentas. Objetiva eliminar os setups } \\
\text { ou, em último caso, mudar os setups internos para externos. }\end{array}$ \\
\hline Seis Sigma & $\begin{array}{l}\text { O Seis Sigma pode ser entendido como uma metodologia utilizada para reduzir continuamente } \\
\text { a variabilidade dos processos e produtos, considerando a situação atual e a meta especificada, } \\
\text { normalmente pelos clientes. Um processo Seis Sigma é aquele no qual é rara a presença de uma } \\
\text { variação fora das especificações. }\end{array}$ \\
\hline Times da Qualidade & $\begin{array}{l}\text { Também conhecidos como círculos de controle da qualidade, são pequenos grupos de colaboradores, } \\
\text { em geral de } 5 \text { a } 10 \text { profissionais, que se reúnem voluntariamente e de forma regular para monitorar, } \\
\text { identificar, analisar e propor soluções para os problemas organizacionais (denominados de projetos), } \\
\text { principalmente àqueles relacionados à produção. }\end{array}$ \\
\hline
\end{tabular}


Apêndice 2. Síntese da estatística descritiva.

\begin{tabular}{|c|c|c|c|c|}
\hline Ferramentas \& Programas & Média & Desvio & Moda & Mediana \\
\hline $5 S$ & 4,03 & 0,98 & 5 & 4 \\
\hline 5W1H & 3,61 & 1,43 & 4 & 4 \\
\hline Benchmarking & 3,38 & 1,21 & 4 & 4 \\
\hline Brainstorming & 3,72 & 1,32 & 5 & 4 \\
\hline SERVQUAL & 1,46 & 0,96 & 1 & 1 \\
\hline CEP & 3,18 & 1,35 & 4 & 3 \\
\hline Diagrama de Ishikawa & 3,61 & 1,39 & 5 & 4 \\
\hline FMEA & 2,82 & 1,42 & 1 & 3 \\
\hline Histograma & 3,34 & 1,42 & 4 & 4 \\
\hline QFD & 2,09 & 1,23 & 1 & 2 \\
\hline CCQ & 2,73 & 1,28 & 3 & 3 \\
\hline 6 Sigma & 2,52 & 1,13 & 3 & 3 \\
\hline BSC & 2,50 & 1,41 & 1 & 3 \\
\hline
\end{tabular}

\begin{tabular}{lcccc}
\hline \multicolumn{1}{c}{ Motivação } & Média & Desvio & Moda & Mediana \\
\hline Pressão dos competidores & 2,89 & 1,37 & 4 & 3 \\
Pressão dos clientes & 3,80 & 1,17 & 4 & 4 \\
$\begin{array}{l}\text { Autoavaliação } \\
\text { Exigência de regulamentação de algum bloco econômico ou }\end{array}$ & 4,01 & 1,12 & 5 & 4 \\
governo externo & 2,63 & 1,52 & 1 & 3 \\
$\begin{array}{l}\text { Marketing } \\
\text { Geração de maior confiabilidade na marca da empresa } \\
\text { perante consumidores }\end{array}$ & 3,70 & 1,17 & 4 & 4 \\
$\begin{array}{l}\text { Oportunidade da empresa torna-se mais atrativa perante } \\
\text { investidores }\end{array}$ & 4,39 & 0,90 & 5 & 5 \\
$\begin{array}{l}\text { Influencia positivamente a imagem da empresa perante a } \\
\text { mídia e a sociedade }\end{array}$ & 3,55 & 1,50 & 5 & 4 \\
$\begin{array}{l}\text { Parte da estratégia geral da empresa } \\
\text { Melhoria na organização interna }\end{array}$ & 4,06 & 1,15 & 5 & 4 \\
Maior eficiência produtiva & 4,27 & 0,97 & 5 & 5 \\
\hline
\end{tabular}

\begin{tabular}{lcccc}
\hline \multicolumn{1}{c}{ Dificuldade } & Média & Desvio & Moda & Mediana \\
\hline Resistência dos funcionários & 3,27 & 1,36 & 4 & 4 \\
Pouco envolvimento da gerência intermediária & 2,72 & 1,43 & 1 & 3 \\
Pouco apoio da alta administração & 2,24 & 1,39 & 1 & 2 \\
Altos custos de implementação & 2,59 & 1,27 & 1 & 3 \\
Dificuldade no entendimento da metodologia e das técnicas & 2,85 & 1,33 & 4 & 3 \\
envolvidas & 2,78 & 1,35 & 4 & 3 \\
Falta de capacitação técnica dos trabalhadores & 2,51 & 1,36 & 1 & 2 \\
Falta de infraestrutura organizacional & & & \\
\hline
\end{tabular}


Apêndice 2. Continuação...

\begin{tabular}{|c|c|c|c|c|}
\hline Benefícios & Média & Desvio & Moda & Mediana \\
\hline Melhoria na cultura organizacional & 4,40 & 0,82 & 5 & 5 \\
\hline Redução dos custos com treinamento & 2,81 & 1,28 & 3 & 3 \\
\hline Aumento no faturamento da empresa & 3,45 & 1,17 & 3 & 4 \\
\hline Melhoria na imagem da empresa & 4,38 & 0,86 & 5 & 5 \\
\hline Melhoria da qualidade nos processos & 4,58 & 0,71 & 5 & 5 \\
\hline Melhoria na comunicação interna & 4,19 & 0,90 & 5 & 4 \\
\hline Diminuição dos desperdícios durante os processos & 4,18 & 0,96 & 5 & 4 \\
\hline Maior retenção de clientes & 3,88 & 1,16 & 5 & 4 \\
\hline Aumento da produtividade & 4,04 & 0,89 & 4 & 4 \\
\hline $\begin{array}{l}\text { Melhor gerenciamento e controle dos aspectos ambientais e } \\
\text { resíduos industriais }\end{array}$ & 3,84 & 1,17 & 5 & 4 \\
\hline Maior visibilidade da empresa junto a clientes e fornecedores & 4,32 & 0,99 & 5 & 5 \\
\hline Maior facilidade na tomada de decisões & 4,19 & 0,92 & 5 & 4 \\
\hline Aumento da satisfação do cliente & 4,36 & 0,79 & 5 & 5 \\
\hline Melhoria no planejamento & 4,38 & 0,79 & 5 & 5 \\
\hline Influência positiva nos demais processos internos de gestão & 4,38 & 0,82 & 5 & 5 \\
\hline Maior conscientização dos empregados & 4,55 & 0,72 & 5 & 5 \\
\hline Maior vantagem competitiva e acesso ao mercado & 4,14 & 0,98 & 5 & 4 \\
\hline Aumento da lucratividade & 3,64 & 1,05 & 4 & 4 \\
\hline Redução do prazo de entrega & 3,61 & 1,13 & 4 & 4 \\
\hline Redução de não conformidades & 4,09 & 1,00 & 5 & 4 \\
\hline Redução dos acidentes de trabalho & 3,79 & 1,19 & 5 & 4 \\
\hline Redução das doenças do trabalho & 3,44 & 1,26 & 3 & 4 \\
\hline Redução dos tempos de afastamento por doenças & 3,32 & 1,25 & 3 & 3 \\
\hline Flexibilidade da produção & 3,72 & 1,14 & 4 & 4 \\
\hline Qualidade dos bens e serviços fornecidos & 4,35 & 0,86 & 5 & 5 \\
\hline Rapidez no lead time de produção e/ou na entrega & 3,86 & 1,05 & 4 & 4 \\
\hline Confiabilidade de produtos e processos & 4,39 & 0,82 & 5 & 5 \\
\hline Redução de custo do produto final & 3,75 & 1,13 & 4 & 4 \\
\hline
\end{tabular}


